\title{
E-Shape Micro strip Patch Antenna on Different Thickness for pervasive Wireless Communication
}

\author{
Neenansha Jain \\ Department of ECE \\ NIST, RGTU \\ Bhopal, India
}

\author{
Anubhuti Khare \\ Department of ECE \\ UIT, RGPV \\ Bhopal, India
}

\author{
Rajesh Nema \\ Department of ECE \\ NIST, RGTU \\ Bhopal, India
}

\begin{abstract}
In this Paper Presents the result for different standard thickness values, and the result is performed by thickness of 31 mile, $\mathrm{Ku}$ - band frequency $12 \mathrm{GHz}$ are gives the best result. The antenna has become a necessity for many applications in recent wireless communications, such as Radar, Microwave and space communication. The proposed antenna design on different thickness and analyzed result of all thickness between $1 \mathrm{GHz}$ to $15 \mathrm{GHz}$ frequency, When the proposed antenna design on a $31 \mathrm{mil}$ RT DUROID 5880 substrate from Rogers-Corp with dielectric constant of 2.2 and loss tangent of 0.0004 . At $12 \mathrm{GHz}$ the verify and tested result on IE3D SIMULATOR are Return loss = 23.08dB, VSWR $=1.151$, Directivity $=11 \mathrm{dBi}$, Gain $=4 \mathrm{dBi}, 3 \mathrm{~dB}$

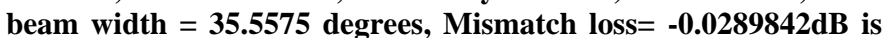
very low, Efficiency $=\mathbf{6 5 . 3 5 4 7 \%}$, All results shown in Simulation results. The Return losses and VSWR results shown in Table 1, Table2 respectively.
\end{abstract}

Keywords- Micro strip antenna; IE3D SIMULATOR; Dielectric; Patch width; Patch Length; Losses; strip width; strip length.

\section{INTRODUCTION}

Ahmed H. Reja [1] proposed Study of Micro Strip Feed Line Patch Antenna experimentally increase the Return Loss $33.6 \mathrm{~dB}$ at $2.5 \mathrm{GHz}$ frequency and VSWR is 1.5 by using CAD (Microwave office 2000 version 3.22) for RT DUROID 5880. Santanu Kumar Behera and Y. Choukiker [2] proposed Design and Optimization of Dual Band Micro Strip Antenna using Practical Swarm Optimization maximize the return loss for dual band Frequency at $2.4 \mathrm{GHz}$ is $-43.95 \mathrm{~dB}$ and at $3.08 \mathrm{GHz}$ is -27.4dB. A A Deshmukh and G Kumar [3] proposed compact L Shape patch broadband Microstrip antenna experimentally increase bandwidth up to $13.7 \%$. Z M Chen [4] further increase bandwidth of this antenna up to $23.7 \%-24.43 \%$. K F Lee [5] proposed U Shape slot shorting post small size Microstrip Antenna and increase bandwidth up to $42 \%$. S C Gao [6] used uniplanar photonic band gap structure for enhancing band width and gain. M Khodier[7] New wideband stacked microstrip antennas for enhancing band width. Major issue for micro strip antenna is narrow Bandwidth.

\section{MATHMATICAL ANALYSIS}

Theoretical analysis and calculations from of all dimensions will be obtained;

The width of the patch element (W) is given by.

$$
W=\frac{c}{2 f_{\circ} \sqrt{\frac{\left(\varepsilon_{r}+1\right)}{2}}}
$$

Substituting $\mathrm{c}=3 \times 10^{8} \mathrm{~m} / \mathrm{s}, \varepsilon \mathrm{r}=2.2$, and $\mathrm{fo}=5 \mathrm{GHz}$, then

$\mathrm{W}=2.3717 \mathrm{~cm}$ or 933.74 mile.

The effective of the dielectric constant (creff) depending on the same geometry $(\mathrm{W}, \mathrm{h})$ but is surrounded by a homogeneous dielectric of effective permittivity ereff, whose value is determined by evaluating the capacitance of the fringing field.

$$
\varepsilon_{\text {reff }}=\frac{\varepsilon_{r}+1}{2}+\frac{\varepsilon_{r}-1}{2}\left[1+12 \frac{h}{W}\right]^{-\frac{1}{2}}
$$

Substituting $\varepsilon \mathrm{r}=2.2, \mathrm{~W}=2.3717 \mathrm{~cm}$, and $\mathrm{h}=0.1575 \mathrm{~cm}$, then

$\varepsilon$ reff $=2.1074 \mathrm{~cm}$ or 829.69 mile.

The effective length (L eff) is given

$$
L_{\text {eff }}=\frac{c}{2 f_{o} \sqrt{\varepsilon_{\text {reff }}}}
$$

Substituting $\mathrm{c}=3 \times 10^{8} \mathrm{~m} / \mathrm{s}$, ereff $=2.0475 \mathrm{~cm}$, and $\mathrm{f} \mathrm{o}=5$ $\mathrm{GHz}$, then $\mathrm{L}_{\text {eff }}=2.0665 \mathrm{~cm}$ or 813.6 mile.

The length extension $(\Delta \mathrm{L})$ is given by:

$$
\Delta L=0.412 h \frac{\left(\varepsilon_{\text {reff }}+0.3\right)\left(\frac{W}{h}+0.264\right)}{\left(\varepsilon_{\text {reff }}-0.258\right)\left(\frac{W}{h}+0.8\right)}
$$

Substituting $\mathrm{E}_{\text {reff }}=2.1074 \mathrm{~cm}, \mathrm{~W}=2.3717 \mathrm{~cm}$, and $\mathrm{h}$ $=0.0787 \mathrm{~cm}$, then $\Delta \mathrm{L}=0.041469 \mathrm{~cm}$ or $16.3266 \mathrm{mile}$.

The actual length $(\mathrm{L})$ of patch is obtained by:

$$
L=L_{e f f}-2 \Delta L
$$

Substituting $\Delta \mathrm{L}=0.041469 \mathrm{~cm}$, and $\mathrm{L}_{\mathrm{eff}}=2.0665 \mathrm{~cm}$, then $\mathrm{L}=1.9835 \mathrm{~cm}$ or $780.92 \mathrm{mile}$. 


\section{ANTENNA DESCRIPTION}

The results of proposed E-Shaped Multiband micro strip patch antenna verified in IE3D Simulator with optimization.

A. Proposed Antenna on 31 mil RT DUROID 5880 substrate:

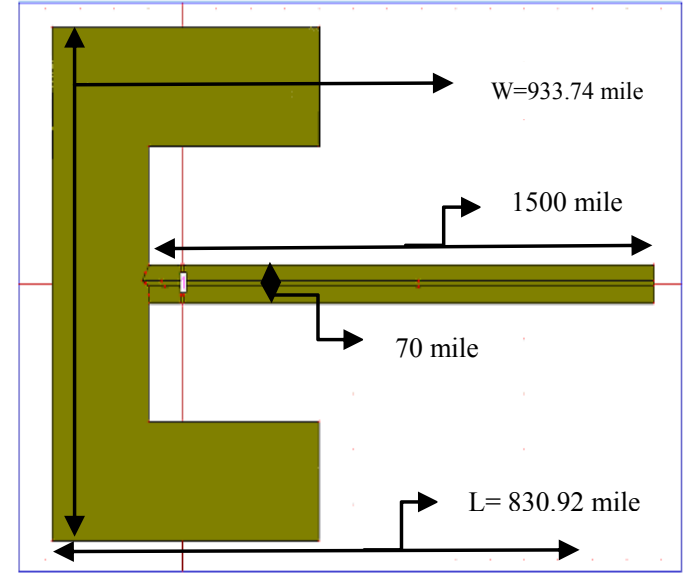

Fig. 1Block Diagram of Proposed Antenna

The Proposed antenna has:-

Proposed Patch length $=780.92+50$ miles

Proposed Patch Width $=933.74$ miles

Strip Path Length $=1500$ miles

Strip Path Width=70miles

Cut width $=300$ miles

Cut depth $=300$ miles

\section{RESULT AND DisSCUSSIONS}

A. Comparison of Different Micro strip Patch Antenna in Different thickness by using optimization in IE3D Simulator for RT DUROID 5880 Substrate.

1) Thickness when $h=15$ mile

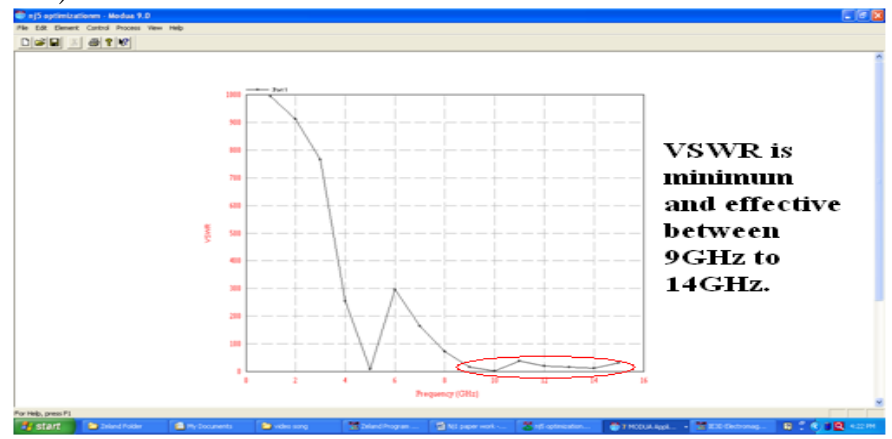

Fig. 2 VSWR Vs Frequency (in GHz)

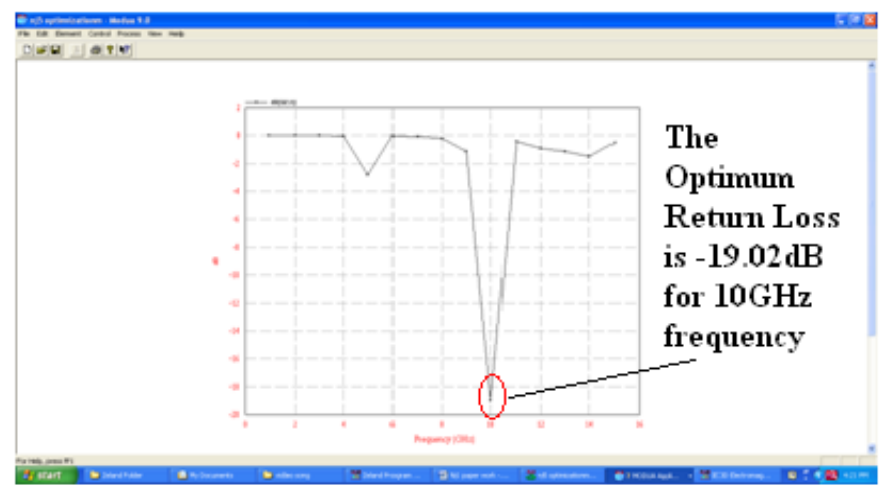

Fig. 3 Return Loss Vs Frequency (in GHz)

2) Thickness when $h=20$ mile.

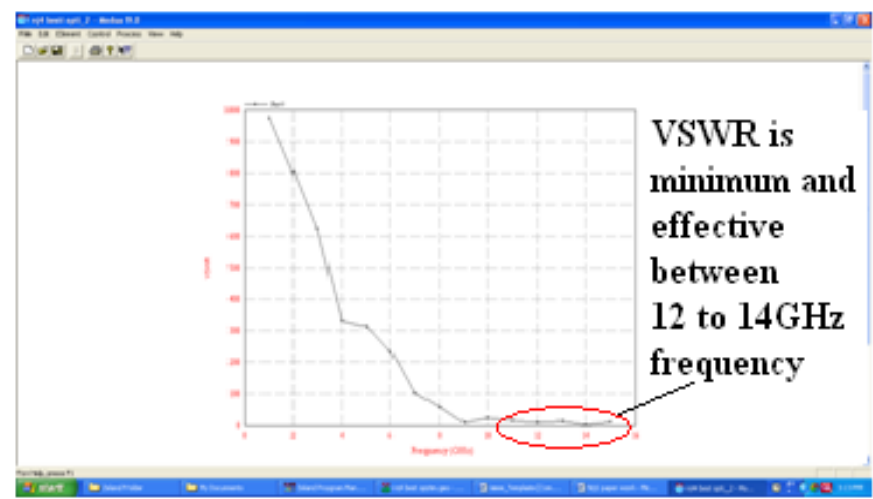

Fig. 4 VSWR Vs Frequency (in GHz)

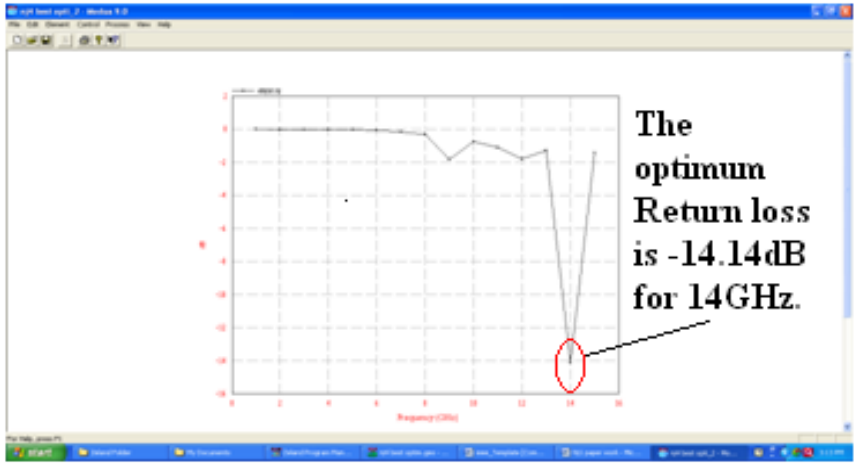

Fig. 5 Return Loss Vs Frequency (in GHz)

3) Thickness when $h=31$ mile

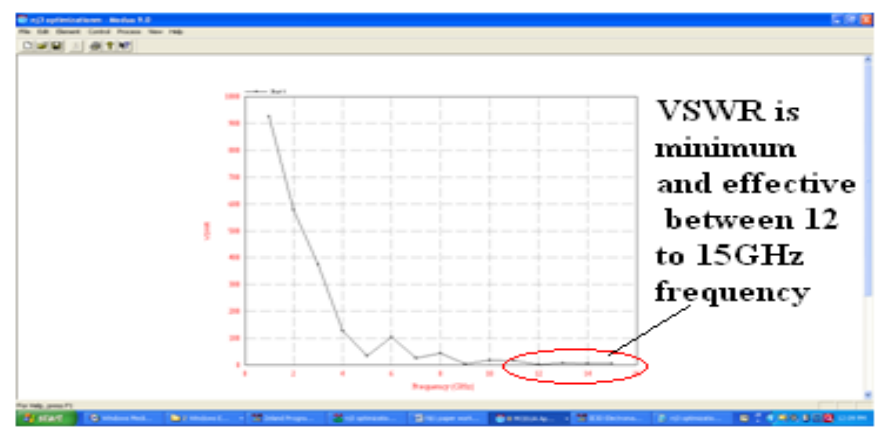

Fig. 6 VSWR Vs Frequency (in GHz) 


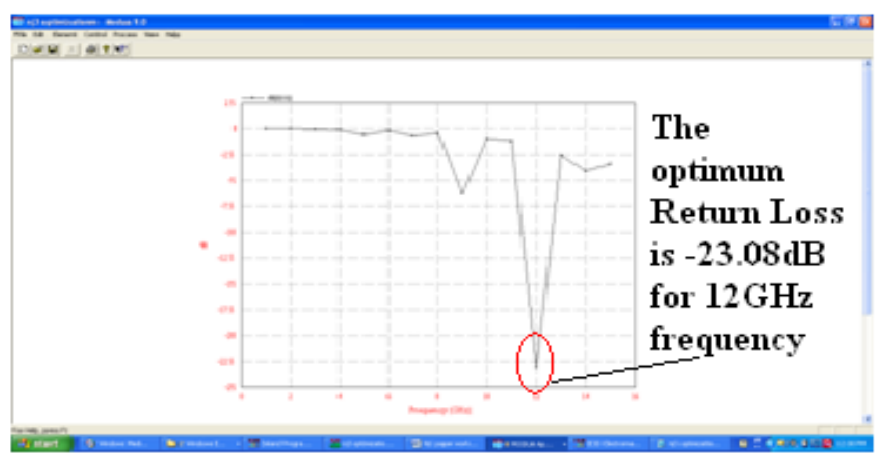

Fig. 7 Return Loss Vs Frequency (in GHz)

4) Thickness when $h=62$ mile

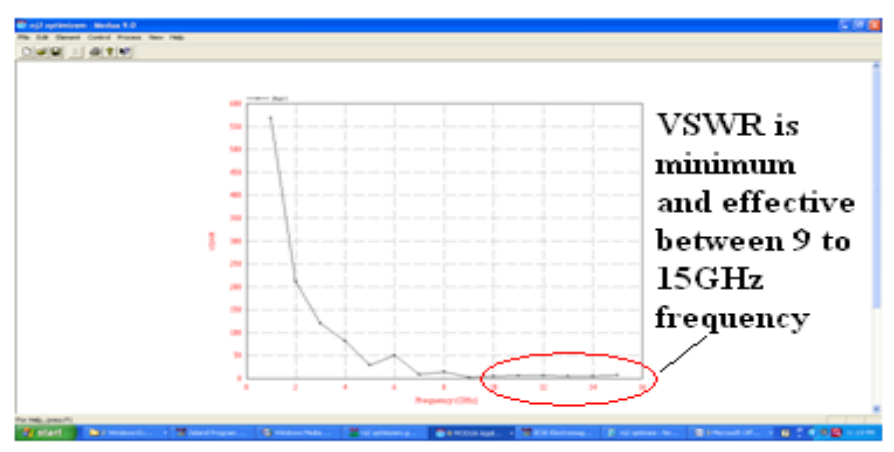

Fig. 8 VSWR Vs Frequency (in GHz)

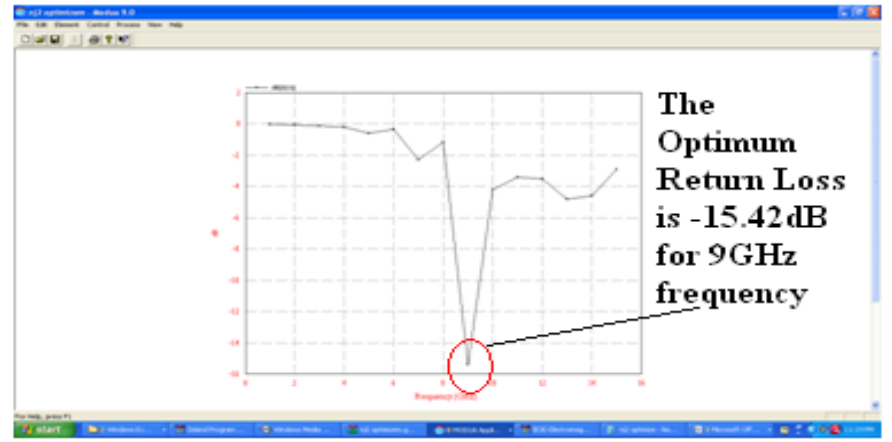

Fig. 9 Return Loss Vs Frequency (in GHz)

5) Thickness when $h=125$ mile

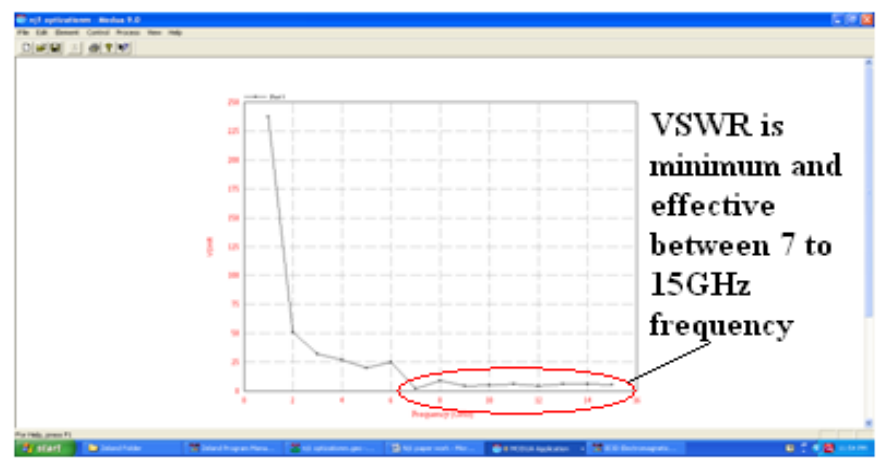

Fig. 10 VSWR Vs Frequency (in GHz)

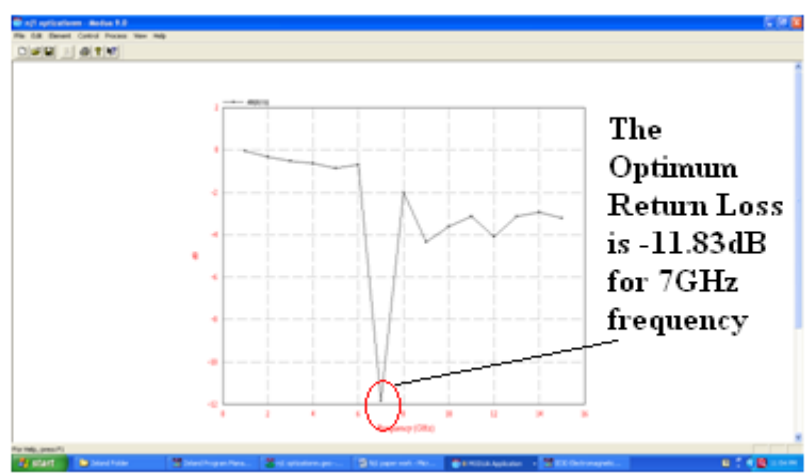

Fig. 11 Return Loss Vs Frequency (in GHz)

B. Best Result Simulated Micro strip Patch Antenna in IE3D Simulator for 31 mil RT DUROID 5880 Substrate

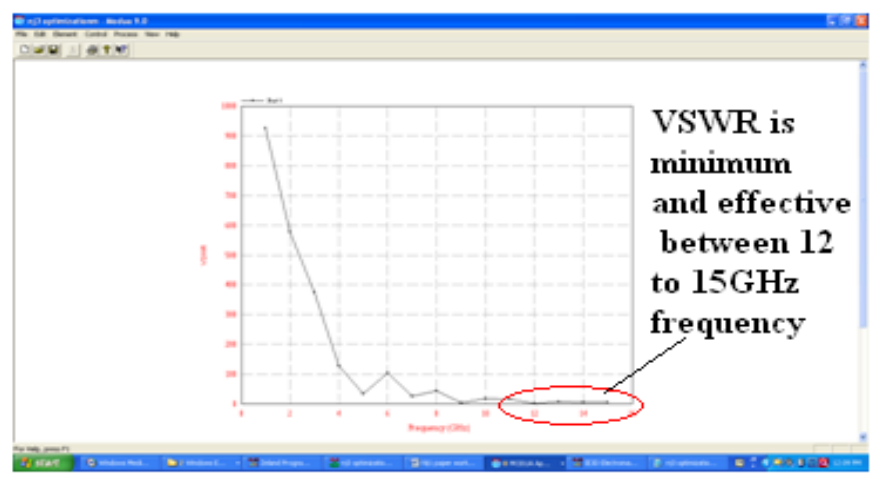

Fig. 12 VSWR Vs Frequency (in GHz)

For proposed design the value of VSWR is effective between $12 \mathrm{GHz}$ to $15 \mathrm{GHz}$, for this value return loss is minimum. At $12 \mathrm{GHz}$ return loss is $-23.08 \mathrm{~dB}$ and VSWR is 1.151 , At $9 \mathrm{GHz}$ VSWR is $2.909,13 \mathrm{GHz}$ VSWR is 6.687 , At $14 \mathrm{GHz}$ VSWR is 4.311 , at $15 \mathrm{GHz}$ VSWR is 5.145 .

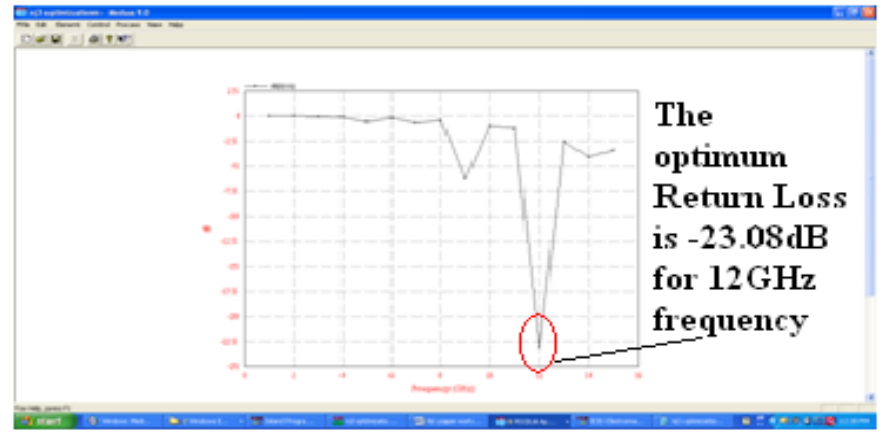

Fig. 13 Return Loss Vs Frequency (in GHz)

The frequency at $10 \mathrm{GHz}$ return losses is -17.71 , at $11 \mathrm{GHz}$ return losses is $-1.222 \mathrm{~dB}$, and at $13 \mathrm{GHz}$ return losses reduce very significantly $-23.08 \mathrm{~dB}$. 


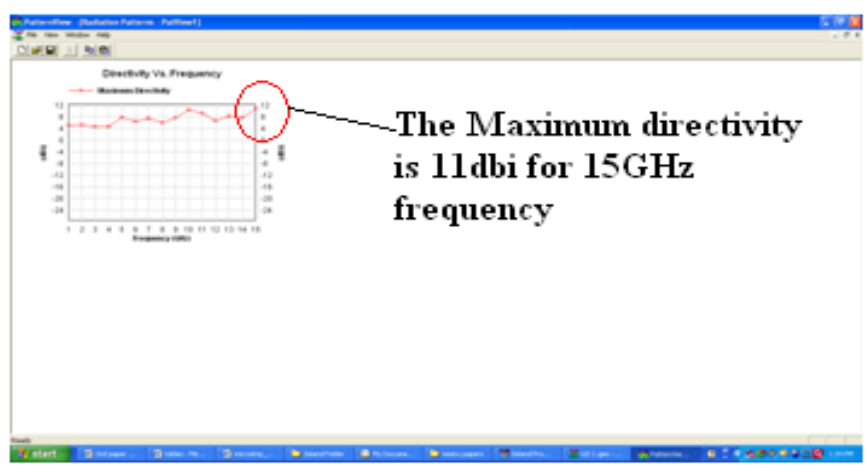

Fig. 14 Directivity Vs Frequency (in GHz)

At $10 \mathrm{GHz}$ frequency Directivity is $11 \mathrm{dBi}$, at $12 \mathrm{GHz}$ Directivity is $7 \mathrm{dBi}$, at $13 \mathrm{GHz}$ Directivity is $8 \mathrm{dBi}$, and at 15 $\mathrm{GHz}$ Directivity is $11 \mathrm{dBi}$.

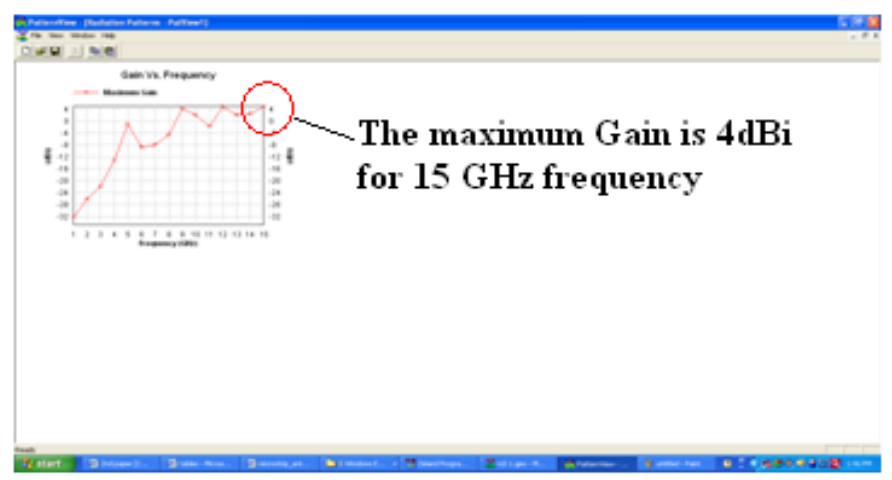

Fig. 15 Gain Vs Frequency (in GHz)

At $10 \mathrm{GHz}$ Frequency Gain is $3 \mathrm{dBi}$, at $12 \mathrm{GHz}$ Gain is $5 \mathrm{dBi}$, at $13 \mathrm{GHz}$ Gain is $2 \mathrm{dBi}$, and at $15 \mathrm{GHz}$ Gain is $4 \mathrm{dBi}$.

\section{Radiation Pattern for $13 \mathrm{GHz}$ Frequency:}

Study of different Azimuth pattern and Elevation pattern in IE3D. Analyzed radiation characteristic of antenna at $13 \mathrm{GHz}$ shown in figure.

\section{1) 2D Polar Radiation pattern}

a) Elevation Pattern

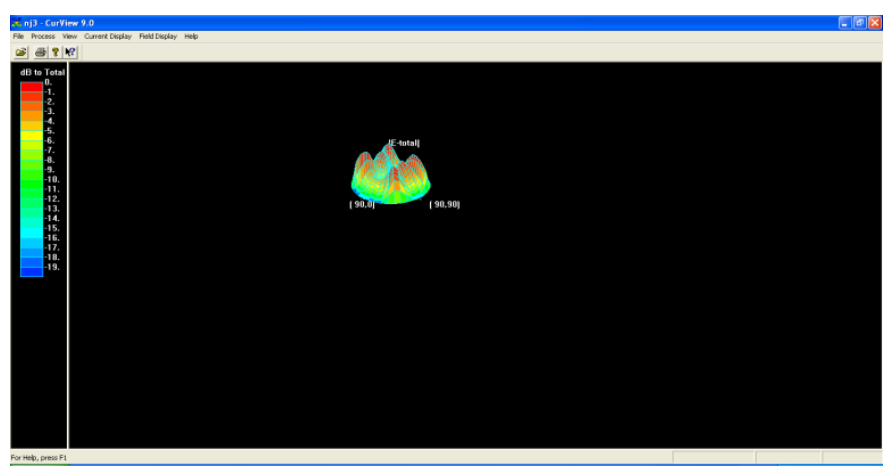

Fig. 16 Elevation Pattern of E Maximum

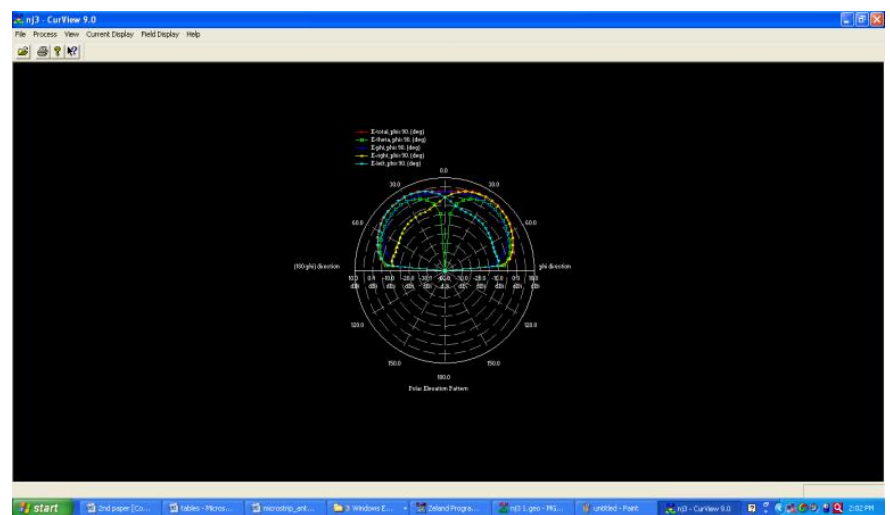

Fig. 17 Elevation Pattern of E Total, E Right, E Left, E Theta, E Phi at Phi=90 (deg)

b) Azimuth Pattern

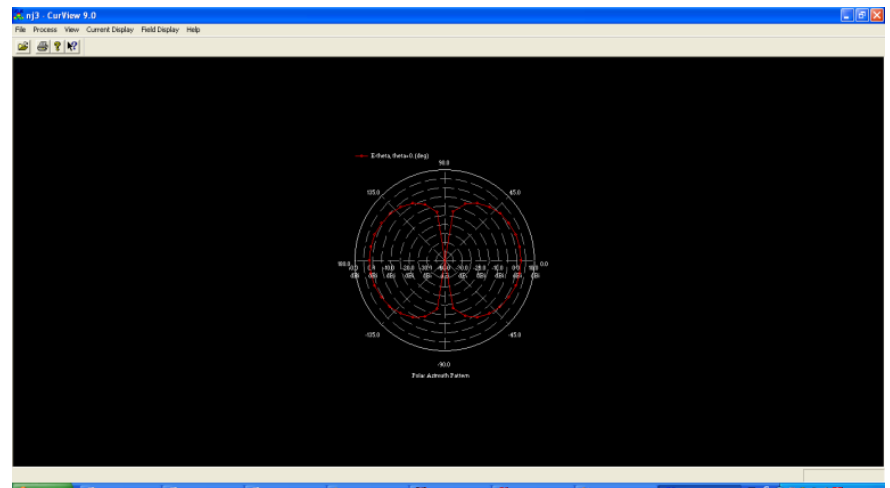

Fig. 18 Azimuth Pattern of E Theta $=0(\mathrm{deg})$

2) Axial Ratio Pattern

a) Elevation Pattern

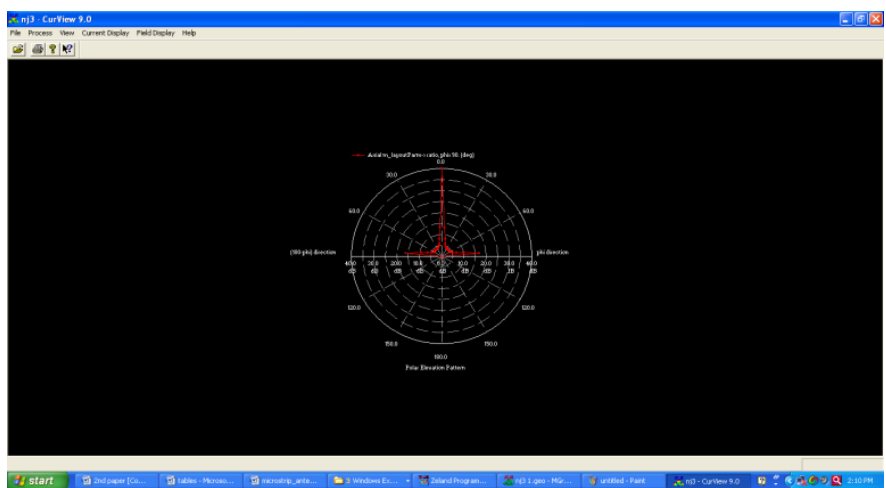

Fig. 19 Axial Pattern of Phi= 90(deg)

b) Azimuth Pattern 


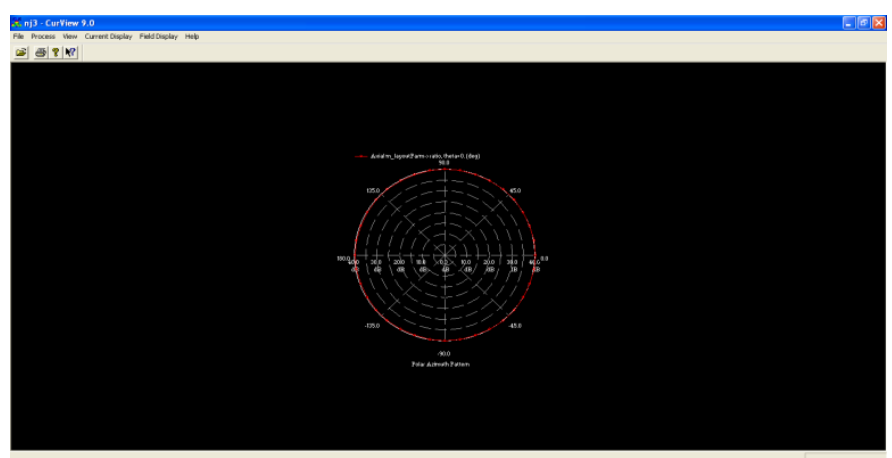

Fig. 20 Axial Pattern of theta $=0(\mathrm{deg})$

\section{3) 3D Pattern Display}

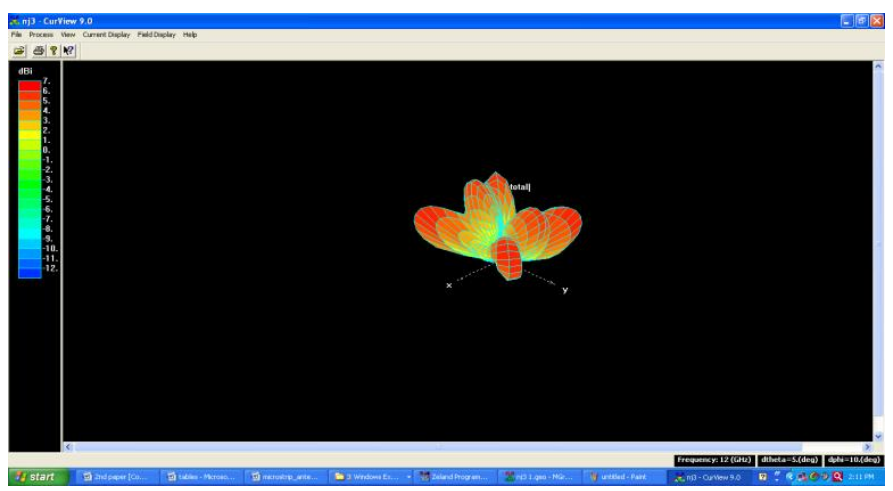

Fig. 21 Elevation Pattern at E-total

\section{4) 2D Radiation Pattern}

a) Elevation Pattern

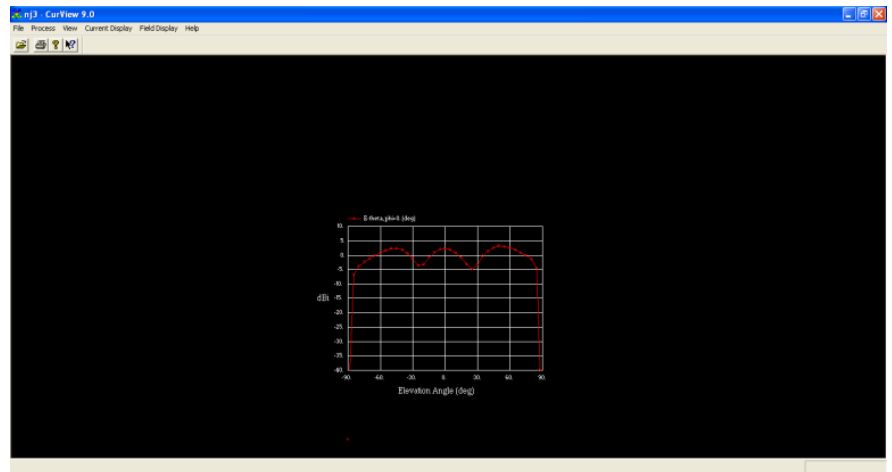

Fig. 22 Elevation Pattern at E-theta at phi=0(deg)

b) Azimuth Pattern

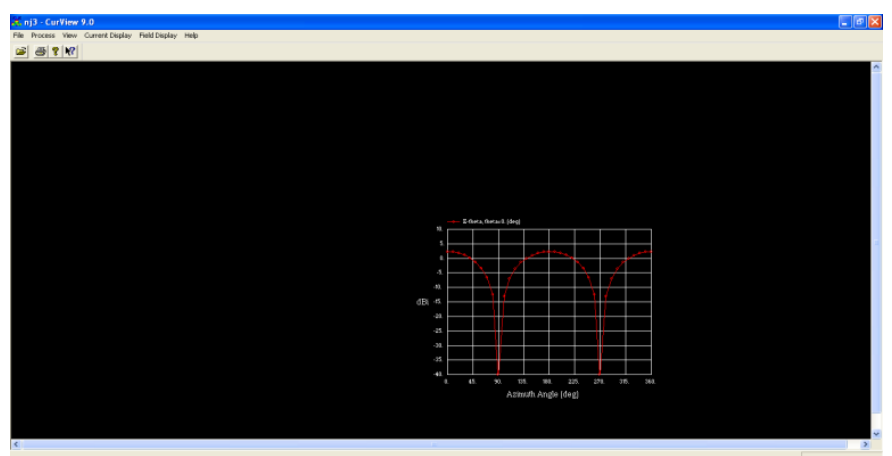

Fig. 23 Azimuth Pattern at E-total at theta=0(deg)

\section{CONCLUSION}

Micro strip antennas have become a rapidly growing area of research. Their potential applications are limitless, because of their light weight, compact size, and ease of manufacturing. One limitation is their inherently narrow bandwidth. However, recent studies and experiments have found ways of overcoming this obstacle. A variety of approaches have been taken, including modification of the patch shape, experimentation with substrate parameters, Most notably mobile communication systems where many frequency ranges could be accommodated by a single antenna. We here design simple and low costlier patch antenna for pervasive wireless communication by using different patch length. The transmission line model seems to be the most instructive in demonstrating the bandwidth effects of the changing the various parameters. When the proposed antenna design on a $31 \mathrm{mil}$ RT DUROID 5880 substrate from Rogers-Corp with dielectric constant of 2.2 and loss tangent of 0.0004 . The proposed antenna give best result when antenna has standard thickness is 31 mile and after optimization addition of extra length is 50mile patch length and some little changes of patch width and more feed line length. The proposed frequency range $12 \mathrm{GHz}$ (Ku Band) and Analysis Radiation Characteristics of micro strip Antenna by IE3D Simulator. The results of proposed designing are effective between $1 \mathrm{GHz}-15 \mathrm{GHz}$. proposed antenna simulated in IE3D Simulator. The optimum results of proposed antenna verify and tested in IE3D SIMULATOR. The simulated results of IE3D at $13 \mathrm{GHz}$ is Return loss $=-23.08 \mathrm{~dB}$, VSWR $=1.151$, Directivity $=11 \mathrm{dBi}$, Gain $=4 \mathrm{dBi}, 3 \mathrm{~dB}$ beam width $=35.5575$ degrees, Mismatch loss $=-0.0289842 \mathrm{~dB}$ is very low, Efficiency= $65.3547 \%$, Total Radiated Power $=0.00649199 \mathrm{~W}$, Average Radiated Power $=0.000516616 \mathrm{~W} / \mathrm{s}$ and Input Radiated Power at ports $=0.009973348$. The proposed $31 \mathrm{mil}$ RT DUROID 5880 substrate E-Shaped multiband micro strip antenna effective work on $12 \mathrm{GHz}(\mathrm{Ku}$ Band) the proposed antenna work very effectively for pervasive wireless communication. 
TABLE1: Frequency (in GHz) Vs Return Losses in $\mathrm{dB}[\mathrm{s}(\mathrm{i} \mathrm{j})]$ for Different Thickness

\begin{tabular}{|c|c|c|c|c|c|}
\hline $\begin{array}{c}\text { Freq } \\
\mathbf{G H z}\end{array}$ & $\begin{array}{c}\mathbf{d B}[\mathbf{S}(\mathbf{1 , 1})] \\
\mathbf{f o r} \mathbf{h}=\mathbf{1 5 m i l e}\end{array}$ & $\begin{array}{c}\mathbf{d B}[\mathbf{S}(\mathbf{1}, \mathbf{1})] \\
\mathbf{f o r} \mathbf{h = 2 0 m i l e}\end{array}$ & $\begin{array}{c}\mathbf{d B}[\mathbf{S}(\mathbf{1}, \mathbf{1})] \\
\mathbf{f o r} \mathbf{h}=\mathbf{3 1} \text { mile }\end{array}$ & $\begin{array}{c}\mathbf{d B}[\mathbf{S}(\mathbf{1}, \mathbf{1})] \\
\text { for h=62mile }\end{array}$ & $\begin{array}{c}\mathbf{d B}[\mathbf{S}(\mathbf{1 , 1})] \\
\mathbf{f o r} \mathbf{h}=\mathbf{1 2 5} \text { mile }\end{array}$ \\
\hline 1 & $-1.748 \mathrm{e}-002$ & $-1.784 \mathrm{e}-002$ & $-1.88 \mathrm{e}-002$ & $-3.056 \mathrm{e}-002$ & $-7.317 \mathrm{e}-002$ \\
\hline 2 & $-1.909 \mathrm{e}-002$ & $-2.163 \mathrm{e}-002$ & $-3.011 \mathrm{e}-002$ & $-8.247 \mathrm{e}-002$ & -0.3412 \\
\hline 3 & $-2.273 \mathrm{e}-002$ & $-2.793 \mathrm{e}-002$ & $-4.655 \mathrm{e}-002$ & -0.1457 & -0.5498 \\
\hline 4 & $-6.832 \mathrm{e}-002$ & $-5.278 \mathrm{e}-002$ & -0.1371 & -0.2139 & -0.6493 \\
\hline 5 & -2.835 & $-5.589 \mathrm{e}-002$ & -0.535 & -0.6108 & -0.8795 \\
\hline 6 & $-5.886 \mathrm{e}-002$ & $-7.422 \mathrm{e}-002$ & -0.1688 & -0.3482 & -0.6976 \\
\hline 7 & -0.1057 & -0.1715 & -0.6865 & -2.329 & -11.83 \\
\hline 8 & -0.2456 & -0.309 & -0.3989 & -1.206 & -2.023 \\
\hline 9 & -1.135 & -1.828 & -6.225 & -15.42 & -4.345 \\
\hline 10 & -19.02 & -0.7607 & -1.024 & -4.22 & -3.638 \\
\hline 11 & -0.4599 & -1.109 & -1.222 & -3.419 & -3.147 \\
\hline 12 & -0.9343 & -1.808 & -23.08 & -3.531 & -4.105 \\
\hline 13 & -1.149 & -1.305 & -2.617 & -4.851 & -3.142 \\
\hline 14 & -1.502 & -14.14 & -4.104 & -4.615 & -2.962 \\
\hline 15 & -0.5566 & -1.461 & -3.42 & -2.908 & -3.22 \\
\hline
\end{tabular}

TABLE2: Frequency (in GHz) Vs. VSWR for Different Thickness

\begin{tabular}{|c|c|c|c|c|c|}
\hline $\begin{array}{l}\text { Freq } \\
\text { GHz }\end{array}$ & $\begin{array}{c}\text { VSWR } \\
\text { for } h=15 \text { mile }\end{array}$ & $\begin{array}{c}\text { VSWR } \\
\text { for } h=20 \text { mile }\end{array}$ & $\begin{array}{c}\text { VSWR } \\
\text { for } h=31 \text { mile }\end{array}$ & $\begin{array}{c}\text { VSWR } \\
\text { for } h=62 \text { mile }\end{array}$ & $\begin{array}{c}\text { VSWR } \\
\text { for } h=125 \text { mile }\end{array}$ \\
\hline 1 & 993.9 & 973.8 & 924.1 & 568.5 & 237.4 \\
\hline 2 & 910.1 & 803.1 & 576.9 & 210.6 & 50.92 \\
\hline 3 & 764.1 & 621.9 & 373.2 & 119.2 & 31.61 \\
\hline 4 & 254.3 & 329.1 & 126.7 & 81.22 & 26.77 \\
\hline 5 & 6.183 & 310.8 & 32.48 & 28.45 & 19.77 \\
\hline 6 & 295.2 & 234.1 & 102.9 & 49.9 & 24.92 \\
\hline 7 & 164.3 & 101.3 & 25.32 & 7.505 & 1.688 \\
\hline 8 & 70.73 & 56.22 & 43.56 & 14.42 & 8.627 \\
\hline 9 & 15.33 & 9.536 & 2.909 & 1.408 & 4.081 \\
\hline 10 & 1.252 & 22.85 & 16.99 & 4.198 & 4.844 \\
\hline 11 & 37.78 & 15.69 & 14.24 & 5.146 & 5.581 \\
\hline 12 & 18.61 & 9.646 & 1.151 & 4.988 & 4.311 \\
\hline 13 & 15.15 & 13.33 & 6.687 & 3.674 & 5.588 \\
\hline 14 & 11.6 & 1.489 & 4.311 & 3.852 & 5.922 \\
\hline 15 & 31.22 & 11.91 & 5.145 & 6.029 & 5.456 \\
\hline
\end{tabular}




\section{ACKNOWLEDGMENT}

The Authors would like to thanks Principal \& H.O.D, Electronics Department of NRI.Engg.College, Patel Nagar for their support and Encouragements, and Electronics Department of NRI Engg.College, Patel Nagar for given testing and development facility for this work.

\section{REFERENCES}

[1] Ahmed H. Reja "Study of Micro Strip Feed Line Patch Antenna", Antennas and Propagation International Symposium, vol. 27, pp. 340-342 December 2008 .

[2] Sahntanu Kumar Behera and Y. Choukiker, "Design and Optimization of Dual Band Micro Strip Antenna Using Practicle Swarm Optimization Technique," in Springer Science+Business Media, LLC, pp. 1346-1354, 2010.

[3] A. A. Deshmukh and G. Kumar, "Compact broadband gap-coupled shorted L-shaped microstrip antennas," in IEEE Antennas and Propagation International Symposium, vol 1, (Baltimore, Maryland), pp. 106-109, IEEE, July 2001.

[4] Z. M.Chen and Y.W.M. Chial, "Broadband probe-fed L-shaped plate antenna," Microwave and Optical Technology Letters, vol. 26, pp. 204206, 1985.

[5] K. F. Lee, K. M. Luk, K. F. Tong, Y. L. Yung, and T. Huynh, "Experimental study of the rectangular patch with a U-shaped slot," in IEEE Antennas and Propagation International Symposium, vol. 1, (Baltimore, Maryland), pp. 10-13, IEEE, July 1996.

[6] S. C. Gao, L. W. Li, M. S. Leong, and T. S. Yeo, "Design and analysis of a novel wideband microstrip antenna," in IEEE Antennas and Propagation International Symposium,vol. 1, (Boston, Massachusetts), pp. 90-93, IEEE, July 2001.

[7] M. Khodier and C. Christodoulou, "A technique to further increase the bandwidth Of stacked microstrip antennas," in IEEE Antennas and Propagation International Symposium, vol. 3, (Salt Lake City, Utah), pp. 1394-1397, IEEE, July 2000.

[8] A.Shackelford, K. F. Lee, D. Chatterjee, Y. X. Guo, K. M. Luk, and R. Chair, "Smallsize wide bandwidth microstrip patch antennas," in IEEE Antennas and Propagation International Symposium,vol. 1, (Boston, Massachusetts), pp. 86-89, IEEE, July 2001

[9] F. Yang, X. -X. Zhang, X. Ye, and Y. Rahmat-Samii, "Wide-Band E Shaped Patch Antennas for Wireless Communications," in IEEE Trans. Antennas Propagation, vol. 49, no. 7, pp. 1094-1100, July. 2001.

[10] K. -L. Wong and W. -H. Hsu, "A Broad-Band Rectangular PatchAntenna with a Pair of Wide Slits," IEEE Trans. Antennas Propagation, vol. 49, no. 9, pp. 1345-1347, Sept. 2001.

[11] Tong K.F., Wong T.P.: "Circularly polarized U-slot antenna”, IEEE Trans. Antennas Propagation, 2007, 55, (8), pp. 2382-2385 .

[12] Salonen P, "Dual-band E-shaped patch wearable textile antenna,"Antennas and Propagation Society International Symposium, 2005 IEEE. 2005; 1A:466,469 Vol. 1A.

[13] Murad NA, "Microstrip U-shaped dual-band antenna. Applied Electromagnetics,”, 2005 APACE 2005 Asia-Pacific Conference on. 2005:4 pp..

[14] Tong K.F., Wong T.P.: "Circularly polarized U-slot antenna", IEEE Trans. Antennas Propagation, 2007, 55, (8), pp. 2382-2385.

[15] Tanaka T., Houzen T., Takahashi ITO K, "Circularly polarized Printed antenna combining slots and patch", IEICE Trans. Communication., 2007, E90-B, (3), pp. 621-628.

[16] M. T. Islam, M. N. Shakib and Norbahiah Misran,"High gain microstrip patch antenna", European Journal of Scientific Research,vol.32 No.2, pp.187-193,2009.

[17] C.A. Balanis, “Antenna theory”, John Wiley, 1982, pp 727-734.

[18] Nasimuddin Z.N. Chen "Aperture coupled asymmetrical c-shaped slot microstrip antenna for circular polarization", IET Microwave Antennas Propag. , Vol. 3, Iss. 3, pp. 372-378, 2009.

[19] Shivnarayan \& Babu R Vishvakarma "Analysis of notch-loaded patch for dual-band operation", Indian Journal of Radio \& Space Physics.Vol.35, pp.435-442.

[20] Mohammad A. A. Subhi H. Ahmad A. K. and Juma S. M. "Cavity model analysis of rectangular micro strip antenna operating in TM03 mode", IEEE proc. pp. 0-2218-2223, 2006.

[21] S. K Satpathy, Vijay Srinivasan, K P Ray and G Kumar, "Compact microstrip antennas for personal mobile communication", IEEE proc.pp. 245-248, 1998.

[22] Kuo, J.S. and K.L., Wong, 2001. "A compact microstrip antenna with meandering slots in the ground plane", Microwave and Opical Technology Letters 29(2), pp. 95-97.

[23] Sze, J.Y. and K.L., Wong, 2000. "Slotted rectangular microstrip antenna for bandwidth enhancement", IEEE Transactions on Antennas and Propagation 48, pp. 1149-1152.

[24] Targonski, S.D., R.B., Waterhouse, and D.M., Pozar, 1998. "Design of wide-band aperture stacked patch microstrip antennas", IEEE Transactions on Antennas and Propagation 46(9), pp. 1245-1251.

\section{AUTHORS PROFILE}

Dr. Anubhuti khare (BE, MTECH, PHD) working as a Professor in Electronics and communication department UIT RGPV, Bhopal (M.P.). Email:anubhutikhare@gmail.com

Phone no: 09425606502,

Rajesh Nema (BE, MTECH, PHD Pursuing) Working as a Assistant Professor in Electronics and communication department NIIST ENGG College Bhopal. The degree of B.E. secured in Electronics and Communication engineering. He secured M.Tech in Electronics and Communication engineering MANIT University. $\mathrm{He}$ is currently pursuing PHD in Electronics and Communication engineering

Author Address: Rajesh Nema E7/128 Ashoka society arera colony Bhopal M.P India Pin code 462016

Email: rajeshnema2010@rediffmail.com

Phone no: 09893216819

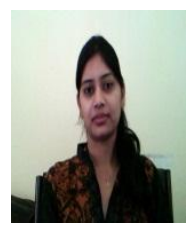

Miss Neenansha Jain (BE, MTECH (P)) MTECH student in Electronics and communication department NIIST ENGG College Bhopal(M.P.). She is secured of B.E. in ECE from Shravanabelagola Karnataka, VTU University India in 2007.

Author Address: Neenansha Jain A-157 Indrapuri, J.K.Road, Bhopal M.P India Pin code 462021

Email : neenanshajain2011@gmail.com

Phoneno: 09406582186 